\title{
Recursos hídricos e a proteção jurídica dos deslocados
} internos

\section{Water resources and the legal protection of internal displacers}

Recursos hídricos y la protección jurídica de las personas desplazadas internamente

Rodrigo Freschi Bertoloa ${ }^{1}$ Leonice Domingos dos Santos Cintra Lima ${ }^{2}$

${ }^{1}$ Mestre em Ciências Ambientais pela Universidade Brasil. Especialista em Direito Processual pela Unama. Especialista em Direito do Trabalho e Seguridade Social pelo Centro Universitário Toledo. Especialista em Direito Previdenciário e em Direito Notarial e Registral pela Universidade Anhanguera-Uniderp. Graduação em Direito pelo Centro Universitário de Votuporanga. Especialista em Direito Constitucional pela Unisul/IDP. Sócio-proprietário de Escritório de Advocacia e Professor na Universidade do Brasil.E-mail: r.f.bertolo@bol.com.br

${ }^{2}$ Doutora e Mestre em Serviço Social pela UNESP. Especialista em Metodologia do Serviço Social e em Administração Hospitalar. Graduada em Serviço Social pela UNESP. Docente em Ensino Superior nível de Graduação nas Faculdades Integradas de Santa Fé do Sul (FUNEC), UNIFADRA e Universidade Brasil; e na Pós-Graduação Lato Sensu na Universidade Brasil. Coordenadora do Curso de Serviço Social na Universidade Brasil, Campus São Paulo.

E-mail: lecaclima@yahoo.com.br 
Resumo: A tutela jurídica das pessoas forçadas a migrarem em razão de problemas hídricos é uma questão que é suscitada pelos organismos internacionais tanto quanto pelos nacionais, em razão da falta de previsão específica. Mesmo que inexistentes instrumentos específicos sobre os deslocados internos e os refugiados ambientais, existem regras que podem ser utilizadas para a tutela desses indivíduos. A dignidade da pessoa humana é o centro de todo o sistema jurídico, já que o atual estado de direito é do tipo socioambiental, em que há uma busca pela concretização do mínimo existencial ambiental. Desse modo, o meio ambiente é um direito fundamental, que propaga sua força normativa para as relações envolvendo as pessoas que foram forçadas a migrarem em virtude de questões hídricas e que são tuteladas em virtude da dignidade da pessoa humana, ainda que estes sujeitos se encontrem em situações equiparadas aos apátridas no plano internacional.

Palavra-chave: dignidade; ser humano; tutela jurídica.

\begin{abstract}
The legal protection of people that are forced to migrate in reason of water problems is an issue that is always raised by both international and national organization, because of the lack of specific prevision. Even though there are no specific national instruments, for the displaced people and environmental refugees, there are rules that can be used to guard these individuals. The dignity of the human being is the center of the entire legal system, since the current rule of law is of the socio-environmental type, in which there is a search for the minimum existential environmental. In this way, the environment is a fundamental right that spreads its normative force to relations involving people who have been forced to migrate because of water issues, and who are protected by the dignity of the human being, even if these people are in situations comparable to stateless people at the international level.
\end{abstract}

Keywords: dignity; human being; legal protection.

Resumen: La protección jurídica de las personas obligadas a migrar debido a los problemas del agua es cuestión siempre suscitada, tanto internacional cuanto nacionalmente, debido a la falta de disposición específica. Incluso, ausentes instrumentos específicos sobre los desplazados internos y los refugiados ambientales, hay reglas que se pueden utilizar para la protección de estos individuos. La dignidad de la persona humana es el centro de todo el sistema jurídico, ya que el estado actual del derecho es del tipo socioambiental, donde hay una búsqueda para la realización de un mínimo. Por lo tanto, el medio ambiente es un derecho fundamental que propaga su fuerza normativa a las relaciones que involucran a las personas que fueron obligadas a emigrar en razón de las cuestiones hídricas y que son tutelados en razón de la dignidad de la persona humana, aunque sus situaciones se asemejen a los apátridas a nivel internacional.

Palabras clave: dignidad; ser humano; protección jurídica. 


\section{INTRODUÇÃO}

O Brasil é uma República Federativa, que pressupõe a existência de entidades autônomas, quais sejam, União, Estados-Membros, Distrito Federal e Municípios, com organização político-administrativa descentralizada, tornando-se indispensável a previsão de competências materiais e legislativas a cada uma delas, para garantir a autonomia e independência de um para com o outro.

Atualmente, são recorrentes os casos em que pessoas se veem obrigadas a deixar seus lares, em virtude de problemas hídricos. Essas pessoas deixam suas casas para se reinstalarem em novos locais, os quais, muitas vezes, não possuem infraestrutura para recebê-las. Sabe-se que a água é imprescindível para a própria sobrevivência dos seres humanos.

Nesse sentido, diante de situações hídricas extremas, como, por exemplo, sua escassez, é necessário fazer uma releitura do próprio pacto federativo, devendo a dignidade da pessoa humana ser usada como vetor para dirimir os conflitos existentes.

Identifica-se que a Constituição Federal Brasileira de 1988 assegura a todos os brasileiros um mínimo existencial socioambiental, de modo que cabe ao Estado concretizar os mandamentos constitucionais asseguradores de tais direitos.

A Constituição Federal tem como fundamento a dignidade da pessoa humana, que se apresenta como forma de proteção aos direitos da personalidade, que são os direitos mais elementares e indissociáveis da existência do ser humano e que devem ser minimamente garantidos pelos entes federativos, independentemente de sua origem, bastando a condição de ser humano.

O presente trabalho tem por objetivo reunir bases jurídicas, que sustentem a aplicabilidade de direitos e garantias fundamentais aos deslocados internos, que são aqueles que têm que se mover, de um local para outro, em busca da água, a partir de uma leitura e revisão da legislação existente.

\section{DIREITOS FUNDAMENTAIS}

Entende-se por Direitos fundamentais aqueles intrínsecos aos seres humanos e idealizados como uma forma de coibir o exercício abusivo do 
poder, praticado pelos próprios órgãos do Estado, como meio de garantia da dignidade dos sujeitos.

Segundo Canotilho (1998, p. 373):

Os direitos fundamentais cumprem a função de direito de defesa sob uma dupla perspectiva: (1) constituem, num plano jurídico-objetivo, normas de competência negativa para os poderes públicos, proibindo fundamentalmente as ingerências destes na esfera individual; (2) implicam, num plano jurídico - subjetivo, o poder de exercer positivamente direitos fundamentais (liberdade positiva) e de exigir omissões dos poderes públicos, de forma a evitar agressões lesivas por parte dos mesmos (liberdade negativa).

Observa-se que os direitos e garantias fundamentais, em seus primórdios, mostram-se, sobretudo, na época do movimento político-cultural, denominado constitucionalismo - que embora haja traços de sua utilização desde a antiguidade clássica, foi na idade moderna que ganhou projeção e veio a ser concretizado mais efetivamente na idade contemporânea.

A partir de então, identificou-se que todo Estado deve possuir uma Constituição que estabeleça a organização do poder, limitando a ação do Poder Público e o âmbito de sua atuação. Nessa época, o objetivo do constitucionalismo era instituir uma relação jurídica harmônica, de forma justa para todos.

Garrido, Garrote e Pegoraro (2000, p. 171), analisando a evolução e proteção dos direitos humanos fundamentais, asseguram que: "La proteción de los Derechos Humanos Fundamentales em um sentido jurídico constitucional, empieza con el Estado moderno".

Com a eclosão das Revoluções Americana e Francesa do século XVIII, as declarações de direito e garantias fundamentais ampliaram-se demasiadamente e, desse modo, surgiu a ideia de Estado de Direito.

Nesse sentido, os direitos fundamentais foram criados para restringir a arbitrariedade do Estado, instituindo sua constituição política, estruturação, organização e limitação de seu poder, através da previsão desse rol de direitos e garantias.

É o que entende Moraes (2003, p. 20):

Os direitos humanos fundamentais, portanto, colocam-se como uma das previsões absolutamente necessárias a todas as Constituições, 
no sentido de consagrar o respeito à dignidade humana, garantir a limitação de poder e visar o pleno desenvolvimento da personalidade humana.

Com a evolução cultural do homem, surgiu a ideia de restringir e controlar os abusos de poder praticados pelas autoridades constituídas, tendo sido editadas as primeiras normas jurídicas que limitaram o poder estatal.

Registrem-se os apontamentos jurídicos de Bertolo (2003, p. 21), o qual ensina que "Somente com o constitucionalismo estabelecido, o Estado tornou-se sujeito de direitos e obrigações e teve que respeitar os direitos fundamentais, sob pena de o Poder Judiciário corrigir eventual ilegalidade".

A Declaração Universal dos Direitos do Homem (DUDH) (UNESCO, 1948) afirma que o fundamento da liberdade, da justiça e da paz no mundo está no reconhecimento da dignidade humana e de seus direitos iguais e inalienáveis.

A referida Declaração foi adotada, 1948 do século passado, pela Resolução n. 217 A (III) da Assembleia Geral das Nações Unidas, que reafirmou a necessidade da proteção dos direitos humanos fundamentais, na dignidade e no valor da pessoa humana, objetivando o progresso social e a melhoria das condições de vida.

Importante trazer à baila os ensinamentos de Rezek (2002, p. 211) informando que:

A declaração Universal dos Direitos do Homem não é um tratado, e por isso seus dispositivos não constituem exatamente uma obrigação jurídica para cada um dos Estados representados na Assembléia Geral quando, sem qualquer voto contrário, adotou-se o respectivo texto sob a forma de uma resolução da Assembléia. Por mais de uma vez, ante gestões externas fundadas no zelo pelos direitos humanos, certos países reagiram lembrando a natureza não-convencional da Declaração.

Portanto resta claro que, quando da análise dos direitos fundamentais, deve-se relacioná-los à dignidade da pessoa humana, pois será fundamental todo o direito necessário ao exercício da vida digna. 


\section{EVOLUÇÃO DOS DIREITOS FUNDAMENTAIS NAS CONSTITUIÇÕES BRASILEIRAS}

No Brasil, as Constituições sempre trouxeram em seu conteúdo uma declaração de direitos e garantias fundamentais que, ao longo da história, foram ampliados de forma a atender as necessidades e novas demandas surgidas no campo da vida cotidiana da população.

A primeira Constituição, em termos normativos, a mencionar os direitos do homem foi a Constituição de 1824, em seu artigo 179, no Título VIII (BRASIL, 1824).

A Constituição Federal (CF) de 1891, também trouxe em seu Título III, - Seção II, no art. 72, a previsão de um rol de direitos humanos fundamentais (BRASIL, 1891). Por sua vez, a CF de 1934 (BRASIL, 1934), igualmente, previu um capítulo sobre direitos e garantias fundamentais, repetindo, em seu art. 113 e incisos, o mesmo rol das constituições pretéritas, situação essa também prevista com a CF de 1937 (BRASIL, 1937).

Já a Constituição de 1946 (BRASIL, 1946), além dos direitos humanos fundamentais previstos pelas Constituições anteriores, proclamava, em seu art. 141, "caput" que: "A Constituição assegura aos brasileiros e aos estrangeiros residentes no país a inviolabilidade dos direitos concernentes à vida, à liberdade, à segurança individual e à propriedade, nos termos seguintes [...]" (MORAES, 2003, p. 33).

Nos mesmos moldes das anteriores, a Constituição Federal de 1967 (BRASIL, 1967) também previa um capítulo de direitos e garantias individuais. Embora a Emenda constitucional n. 1 de 1969 (BRASIL, 1969 ) tenha produzido diversas alterações, não houve nenhuma alteração formal no que tange aos direitos humanos fundamentais.

A Constituição Federal de 1988 (BRASIL, 1988) trouxe importantes alterações no que tange aos direitos fundamentais.

Destaca-se que, em seu art. 3ํㅡ, a CF consagrou expressamente o princípio da dignidade humana, como fundamento da República, o que, por si só, deixa explícita a preocupação com a dignidade dos sujeitos, trazendo grande valorização quanto a sua proteção.

Segundo Bulos (2002, p. 49): “A dignidade da pessoa humana é o valor constitucional supremo que agrega em torno de si a unanimidade 
dos demais direitos e garantias fundamentais do homem, expressos nesta Constituição".

Piovesan (2000, p. 297) preleciona que:

A dignidade humana e os direitos e garantias fundamentais vem a constituir os princípios constitucionais que incorporam as exigências de justiça e dos valores éticos, conferindo suporte axiológico ao sistema jurídico brasileiro.

Importante ressaltar que o artigo $5^{\circ}$ desta Constituição (BRASIL, 1988) traz o rol de direitos e garantias fundamentais, que não se esgotam nessa previsão, mas trazem importante norte para o resguardo desses direitos. Nota-se que, inclusive no "caput" desse dispositivo, o legislador constitucional preocupou-se em ressaltar que todos são iguais.

Assim sendo, nota-se que, ao longo das Constituições, houve importante ampliação da proteção dos seres humanos, e atualmente reconhecem-se como fundamentais todos aqueles direitos que visam atender e resguardar a dignidade da pessoa humana.

\section{CARACTERÍSTICAS DOS DIREITOS FUNDAMENTAIS}

Os direitos fundamentais foram inseridos no ordenamento jurídico pátrio com o objetivo principal de proteger a dignidade da pessoa humana, para resguardar a liberdade, as necessidades vitais do homem, cumprindo-se assim o desejo daqueles que promoveram a Revolução Francesa esculpida em três princípios cardeais dos direitos fundamentais, a saber: liberdade, igualdade e fraternidade.

Dessa forma, convém destacar a interpretação dada por Bertolo (2003, p. 21):

Ao falarmos em direitos fundamentais no sentido contemporâneo, devemos reconhecer que são direcionados a todos, indistintamente, razão pela qual será possível extrair que possuem características, embora os doutrinadores não são unânimes na quantidade e na nomenclatura.

A CF assegura os direitos fundamentais, fornecendo meios adequados para que se possam usá-los. Assim, ela determina que os direitos fundamentais têm aplicação imediata. 
Dessa forma, as normas que os asseguram também devem ter aplicação imediata, porém, nunca devem restringir tais direitos, ou seja, mesmo que não haja garantias jurisdicionais, os direitos fundamentais são válidos, visto que essa correlação não se faz necessária. Eles têm como características a historicidade, a universalidade e internacionalização, a concorrência, a irrenunciabilidade, entre outras.

- Historicidade: a historicidade dos direitos humanos fundamentais vem de uma cadeia evolutiva que foi sendo construída no processo de construção da própria história da sociedade, formando assim seu caráter histórico.

- Universalidade e internacionalização: como característica dessa universalidade e internacionalização dos direitos fundamentais apresenta um encontro com o objeto destes, qual seja, o de garantir aqueles direitos essenciais do homem como num todo e, não apenas para determinados Estados, daí a máxima de que os direitos fundamentais são universais, sendo inerentes à condição humana, posição defendida por Canotilho (1998, p. 380-1):

São direitos humanos e não apenas direitos dos cidadãos portugueses, a não ser quando a constituição ou a lei (com autorização constitucional) estabeleça uma 'reserva dos direitos' para os 'nacionais' ou cidadãos portugueses. Há, porém, alguns desvios a estes princípios.

- Limitabilidade: vem de encontro ao fato dos direitos fundamentais não serem absolutos, significando na possibilidade de choque entre direitos fundamentais, implicando a invasão de um em face de outro, situação essa que exige um regime de cessão recíproca; nesses termos prelecionam Araújo e Nunes Júnior (2004, p. 95) "Sempre que o exercício de um direito fundamental colocar o seu titular em choque com o exercente de outro, teremos uma situação de colisão de direitos".

- Concorrência: a referida característica significa que os direitos fundamentais podem ser acumulados, ou seja, podem concorrer entre si. Em um sentido mais elucidativo, Araújo e Nunes Júnior (2004, p. 97):

A verificação da concorrência de direitos fundamentais faz com que uma única situação seja regulamentada por mais de um preceito constitucional. Logo, constitui tarefa de suma importância, pois só com a identificação de todas as normas de regência será possível a definição do regramento e das conseqüências jurídicas específicas. 
- Irrenunciabilidade: como são indisponíveis, os direitos fundamentais são irrenunciáveis, podendo ocorrer o seu não exercício, contudo jamais sua renúncia. A irrenunciabilidade significa que os direitos humanos fundamentais não podem ser renunciados pelos indivíduos, pois se tratam de direitos imprescindíveis para a boa existência dos seres humanos.

\section{ENQUADRAMENTO NAS GERAÇÕES DOS DIREITOS FUNDAMENTAIS}

Gerações dos direitos fundamentais revelam-se como sendo a classificação doutrinária que leva em consideração o surgimento, ou seja, o aparecimento no ordenamento jurídico.

Os direitos fundamentais podem ser classificados em três tipos: os que são relacionados com as pessoas, os quais são chamados de direitos naturais ou individuais e que são indispensáveis ao homem; os direitos civis, que compreendem os direitos naturais, os quais são reconhecidos e protegidos pelas leis civis; e os direitos políticos, aqueles que não são faculdades naturais, mas sim criados a partir das condições e conveniências das leis.

Na Constituição Federal de 1988, os direitos e garantias fundamentais aparecem no Título II, subdivididos em cinco capítulos, sendo eles: direitos individuais e coletivos; direitos sociais; nacionalidade; direitos políticos e partidos políticos (BRASIL, 1988).

Nesse sentido, os Direitos Fundamentais de primeira geração surgiram junto com o constitucionalismo e com a ideia de Estado de direito, no final do século XVII, que dividiram as funções do poder do Estado, de modo que estas fossem atribuídas a órgãos distintos, impedindo a concentração de poderes e o arbítrio de uma ou de um grupo de pessoas.

Os direitos de primeira geração são denominados de direitos civis, ou individuais, e políticos, pois servem de defesa para o indivíduo perante o Estado, bem como preveem liberdades públicas negativas, ou direitos negativos, pois visam fazer com que o Estado não interfira no relacionamento social. Compreendem os direitos de liberdade; direitos e garantias individuais e políticos chamados de liberdades públicas. O direito à vida, abrangendo os direitos da personalidade, portanto, estão inseridos nos direitos fundamentais de primeira geração. 
Porém percebeu-se que de nada adianta apenas proibir o Estado de praticar determinados atos, pois, para que os direitos humanos fundamentais sejam assegurados, o Estado deve protegê-los, dando condições de dignidade para os indivíduos. Assim, observa Tavares (2002, p. 389) quando diz que:

O Estado, que era então visto como um inimigo pessoal e contra o qual urgia defender a liberdade individual, converte-se, já agora, em um "amigo", posto que lhe é incumbida a tarefa de prover às necessidades da comunidade. Contudo, há de se acentuar aqui que não são gerações que se contrapõem entre si, mas, antes, que se complementem.

Portanto é necessário que o Estado proporcione condições para o suprimento das necessidades mínimas dos indivíduos, a fim de que eles possam viver com dignidade, exigindo-se que o Estado forneça as condições para suprir as necessidades individuais e sociais da pessoa humana. Nesse sentido, surgiram os Direitos Fundamentais de segunda geração, também denominados direitos positivos, por trazerem a expectativa de uma participação ativa do Estado.

Progredindo-se, passou-se a falar que direitos fundamentais devem consagrar a fraternidade, proteger o meio ambiente, tendo em vista a manutenção da qualidade de vida dos seres humanos, para lhes proporcionar a paz, como forma de consagração do princípio da solidariedade. Esses direitos estão previstos no art. 225, da Constituição Federal de 1988 (BRASIL, 1988), e passaram a ser reconhecidos como direitos fundamentais de terceira geração.

Observa-se que, a preservação do meio ambiente é fundamental para que haja uma convivência e desenvolvimento social pacíficos entre os seres humanos. Dessa forma, revela-se a importância de assegurar-se os direitos fundamentais de terceira geração.

E por último, destaca-se a existência dos direitos fundamentais de quarta geração, que são frutos das transformações de um mundo globalizado em que novas tecnologias são lançadas, alterando o cotidiano da sociedade, compreendendo, principalmente, os direitos à democracia, à informação e ao pluralismo. 


\section{RECURSOS HÍDRICOS E O MÍNIMO EXISTENCIAL HUMANO}

A questão hídrica e seus problemas ultrapassam os questionamentos envolvendo o uso desarrazoado da água, os conflitos envolvendo uso de água na agricultura e suprimento urbano, a contaminação, as construções de reservatórios nas bacias hidrográficas que afetam os ciclos hidrológicos, biológicos e hidrossociais.

A ausência do recurso hídrico ou o elevado custo para obtê-lo revela seu impacto direto no plano interno, quando se observam os conflitos de interesses envolvendo áreas que acabam sendo superpovoadas em centro urbanos, ocasionando racionamentos de água, bem como esfacelamento de determinadas regiões por ausência do recurso hídrico acessível.

A consecução do princípio da dignidade da pessoa humana pressupõe o respeito à integridade e condições materiais de subsistência garantidos a cada indivíduo por simplesmente existir.

Ao identificar o chamado mínimo existencial necessário para a concretização da dignidade da pessoa humana, é claro que existem aqueles de extrema necessidade, tais como água potável, moradia adequada, saneamento básico, saúde, educação, renda, alimentação etc., cabendo ao Estado suprimir as carências daqueles necessitados.

Nesse passo, os chamados recursos hídricos, ou seja, aqueles relacionados ao uso de água, encontram-se inseridos como sendo um bem indispensável para a própria existência do homem e como um direito fundamental de todo ser humano, de modo que a preservação do mínimo existencial, e, por sua vez, a própria dignidade da pessoa humana, somente ocorrerá se for garantido pelo Estado que todos têm direito à obtenção de recursos hídricos.

\section{PAPEL DOS ESTADOS NA QUESTÃO DOS DESLOCAMENTOS FORÇADOS AMBIENTAIS}

O meio ambiente é visto como um direito fundamental insculpido na Constituição brasileira de 1988 (BRASIL, 1988) e classificado como um direito fundamental de 3 a dimensão.

Trata-se de bem jurídico de extrema importância para a devida consagração da dignidade da pessoa humana e, como tal, se revela em sua concretude com a verdadeira atuação do Estado para garantir esse propósito. 
Tendo em vista a caracterização do meio ambiente como um direito fundamental e, por consequência, sua aplicabilidade imediata (conforme teor do art. 5으, §1으, da CF), aliado ao conteúdo do §2으 do mesmo art. 5으, da CF, em que se permite a atribuição do caráter de direito fundamental a outras normas que não estejam previstas apenas no corpo da Constituição, permite-se a existência de normas consideradas que contêm direitos fundamentais, em tratados internacionais (BRASIL, 1988).

Mendes, Coelho e Branco (2007, p. 225) asseveram que:

Já os direitos chamados de terceira geração peculiarizam-se pela titularidade difusa ou coletiva, uma vez que são concebidos para a proteção não do homem isoladamente, mas de coletividade, de grupos. Tem-se, aqui, o direito à paz, ao desenvolvimento, à qualidade do meio ambiente, à conservação do patrimônio histórico e cultural.

Nesse sentido, a proteção que melhor alcança e assegura a dignidade da pessoa humana sob uma vertente ecológica, tanto no plano interno quanto no internacional, é a que qualifica o meio ambiente como direito fundamental.

O que se identifica nos dias atuais é que não apenas se deve pensar em um Estado Social Democrático, objetivando assegurar direitos de caráter fundamentais de 2 a dimensão, mas sim proteger e efetivar direitos metaindividuais de abrangência coletiva, tendo em vista tratar-se o direito fundamental ao meio ambiente como direito inato de todo e qualquer ser humano, garantindo-se assim a existência digna destes - clara proteção e tutela do próprio gênero humano - consolidando-se os chamados direitos de terceira dimensão/geração.

Tais mudanças e/ou observações pontuais se deram em virtude da alteração de visão antropocêntrica pura para uma visão moderada, alargada, ou, ainda, ecológica.

Sarlet e Fensterseifer (2012, p. 62) asseveram que:

Com efeito, já alinhando a reflexão com o propósito deste capítulo, não nos parece possível excluir de uma compreensão necessariamente multidimensional e não reducionista da dignidade da pessoa humana, aquilo que se poderá designar de uma dimensão ecológica (ou, quem sabe, formulado de um modo integrativo, socioambiental) da dignidade humana, que por sua vez, também não poderá 
ser restringida a uma dimensão puramente biológica ou física, pois contempla a qualidade de vida como um todo, inclusive do ambiente em que a vida humana (mas também a não humana) se desenvolve. É importante, aliás, conferir um destaque especial para as interações entre a dimensão natural ou biológica da dignidade humana e a sua dimensão ecológica, sendo que esta última objetiva ampliar o conteúdo da dignidade da pessoa humana no sentido de assegurar um padrão de qualidade e segurança ambiental mais amplo (e não apenas no sentido da garantia da existência ou sobrevivência biológica), mesmo que muitas vezes esteja em causa em questões ecológicas a própria existência natural da espécie humana, para além mesmo da garantia de um nível de vida com qualidade ambiental.

Diante desse quadro paradigmático, cumpre ressaltar a existência de um mínimo existencial socioambiental, como bem definido por Sarlet e Fensterseifer (2012, p. 96-7):

Na linha de um constitucionalismo socioambiental, afinado com o tratamento conferido pela nossa Lei Fundamental à proteção do ambiente, é nosso objetivo traçar uma primeira reflexão sobre direito fundamental ao mínimo existencial socioambiental, demarcando algumas possibilidades em termos conceituais e de justificação normativa, ou seja, de matriz jurídico-constitucional, além de identificar e comentar, em caráter necessariamente sumário e ilustrativo, aspectos ligados ao problema de sua inserção no contexto mais amplo da justiça (sócio) ambiental e do Estado Socioambiental. Nessa perspectiva, importa rastrear pontos de contato normativo entre os direitos fundamentais sociais e o direito fundamental ao ambiente, explorando a noção de um mínimo existencial de cunho socioambiental. Para além dos direitos já identificados doutrinária e mesmo jurisprudencialmente como "possíveis" integrantes da noção de um mínimo existencial (reconhecidamente controversa, a despeito de sua popularidade), como é o caso de uma moradia digna, de saúde básica, de saneamento básico, da educação fundamental, de uma renda mínima, de assistência social, do acesso da justiça (no caso da assistência jurídica integral e gratuita aos necessitados), de uma alimentação adequada, entre outros, é nosso intento sustentar a inclusão nesse elenco da qualidade e segurança ambiental, objetivando a garantia de uma existência humana digna e saudável, especialmente no que diz com a construção da noção de um bem-estar existencial que tome em conta também a qualidade (e segurança) do ambiente. 
Nesse contexto, é dever do Estado Constitucional Brasileiro, assegurar prestações materiais mínimas propiciadoras do chamado bem-estar sob a ótica de um mínimo existencial ambiental.

\section{DESLOCAMENTO FORÇADO: PESSOAS INTERNAMENTE DESLOCADAS}

Preliminarmente, é de se destacar alguns acontecimentos que marcaram o Brasil, como o desastre na cidade de Mariana, MG, em que houve o rompimento da barragem de contenção de resíduos de mineração, o excesso de chuvas e desabamentos ocorridos recentemente no Brasil, que inclusive se têm tornado repetidos e intensos - situações essas que fizeram com que pessoas migrassem forçadamente. Também se visualizam não de maneira abrupta, mas não menos impactante, as migrações populacionais em virtude de secas no sertão nordestino.

Quando há um problema ambiental de grande repercussão em que a população do local atingido é obrigada a se deslocar, há a necessidade de local para fixar residência dessas pessoas e da tutela de seus direitos.

Incialmente, ao longo da história, as migrações se davam em busca de melhores oportunidades de empregos e de vida, o que acabou gerando políticas de restrições por parte de alguns governos para frear uma avalanche de novas pessoas que migravam em grandes quantidades.

Paralelamente, também houve um aumento de migrações de pessoas em situações de risco com a violação dos direitos humanos, implicando reconhecimento da necessidade das autoridades internacionais em tutelar os chamados refugiados de guerra, aprovando-se, em 1951, a Convenção Relativa ao Estatuto dos Refugiados e a criação do Alto Comissariado das Nações Unidas para os Refugiados (1951).

Deslocado interno, segundo a definição proposta pelo Representante Especial do Secretário-Geral das Nações Unidas para Deslocados Internos, no instrumento chamado Princípios Orientadores Relativos aos Deslocados Internos, de 1998, seriam:

Pessoas ou grupos de pessoas compelidas a fugir de seus domicílios ou dos locais em que residiam habitualmente, particularmente em consequência de, ou com vistas a evitar, os efeitos 
de conflitos armados, tensões internas, violações de direitos humanos ou desastres naturais ou provocados pelo homem, e que não atravessaram uma fronteira nacional reconhecida internacionalmente.

Frise-se que a responsabilidade primária pelos deslocados internos é do próprio Estado a que estão vinculados os indivíduos em migração forçada ambiental, tendo nosso próprio ordenamento constitucional dispositivos que devem ter suas óticas ampliadas de alcance interpretativo para poder abarcar situações de proteção jurídica, tais como o direito de liberdade de locomoção -insculpido no art. 5, inciso XV, da CF, garantindo a livre escolha de residência; o direito à moradia, insculpido no art. 7, inciso IV, da CF; o direito de ir e vir, previsto no artigo 5o, inciso XV, da CF (BRASIL, 1988).

A proteção da propriedade é uma das maiores lacunas da proteção jurídica dos deslocados internos- a vulnerabilidade associada a tais pessoas implica uma necessidade de normas que protejam a sua propriedade, como a criação de um mecanismo de restituição ou compensação por essas perdas torna-se imprescindível.

Outro reflexo conflitivo com a ausência de recursos hídricos e/ou sua drástica diminuição revela-se em conflitos federativos, envolvendo entes federativos, já que diversas bacias hidrográficas e/ou rios cortam mais de um Estado e mais de um município, de modo que atitudes político-governamentais tomadas em um refletem nos demais, surgindo conflitos, pois um desses entes acabará sofrendo consequências prejudiciais em seu abastecimento, atingindo diretamente a população.

Nesse contexto, podemos vir a ter a necessidade de afastamento temporário da autonomia que cada ente federativo possui, com a implantação da intervenção federal e estadual, conforme cada caso e de acordo com os artigos 34, 35 e 36 da CF (BRASIL, 1988).

E a princípio, somente o caso em concreto e a proporcionalidade como técnica de resolução de conflito, é que servirão para uma melhor decisão sobre o conflito envolvendo recursos hídricos, já que se teriam dos dois lados direitos fundamentais em pé de igualdade.

Nesse contexto, a proteção jurídica internacional, no que tange aos deslocados internamente, implica registrar-se a figura do Direito 
Internacional dos Direitos Humanos (DIDH), que se revela como o conjunto de princípios e normas que regulam internacionalmente a questão dos direitos humanos e, por via de consequência, abrangem também os chamados deslocados internos.

Nos instrumentos normativos internacionais, que visam assegurar os direitos dos deslocados internos e que possuem aplicabilidade no ordenamento jurídico brasileiro, tornam-se dignos de nota os seguintes pontos: proteção contra o deslocamento forçado, advinda da liberdade de locomoção e residência, reconhecido na Declaração Universal dos Direitos Humanos (DUDH) (UNESCO, 1948), em seu artigo 9o; b) O direito de permanência em seu local de residência, derivado da liberdade de locomoção - reconhecido no artigo 13 da DUDH e também se encontra garantido no artigo 12 do Pacto Internacional dos Direitos Civis e Políticos (PCP, 1966). O primeiro declara que "toda pessoa tem direito à liberdade de locomoção e residência dentro das fronteiras de cada Estado". Por sua vez, o artigo 12 do PCP estabelece que "toda pessoa que se encontre legalmente no território de um Estado terá o direito de nele livremente circular e escolher sua residência"; c) direito à moradia garantido no artigo 11 do Pacto Internacional dos Direitos Econômicos, Sociais e Culturais (PESC, 1966); d) A DUDH também afirma que "toda pessoa tem o direito de deixar qualquer país, inclusive o próprio, e a ele regressar" (artigo 13) e que "toda pessoa vítima de perseguição tem o direito de procurar e de gozar asilo em outros países" (artigo 14); e) Todo deslocado interno tem direito de buscar refúgio em país vizinho ao seu e, caso cumpra os requisitos contidos na definição da Convenção de 1951, adquirir status de refugiado.

\section{CONCLUSÃO}

Diante de todo um novo conceito de Estado, em que ao ser humano deve ser conferido um rol de direitos mínimos que garantam a sua vida digna, dentre eles, o meio ambiente sadio e equilibrado, o que engloba, de modo primordial, o uso da água, revela-se, de suma importância, a análise dos conflitos envolvendo o deslocamentos de pessoas, dentro do território nacional, por motivos de conflitos envolvendo a água. 
Nota-se que o deslocamento por motivos hídricos é realidade no Brasil. No entanto observa-se que não existe, no ordenamento jurídico brasileiro, nenhuma norma que tutele especificadamente os deslocados internos proveniente de questões ambientais e, mais especificadamente, ainda, sobre recursos hídricos.

Diversos problemas surgem com os deslocamento de pessoas por motivos hídricos, exemplificativamente elencando-se o resguardo da moradia e da propriedade, que são direitos fundamentais.

A despeito da falta de previsão legislativa específica, nota-se que a Constituição Federal de 1988 previu um rol de direitos e garantias fundamentais, para que o sujeito exerça sua vida com dignidade.

A partir da descrição desses direitos, o presente trabalho buscou apresentar instrumentos para a proteção jurídica dos deslocados internos, com o propósito de tutelar as necessidades dos indivíduos que se encontrarem em situações de extrema vulnerabilidade.

Destarte, em que pese à necessidade urgente de elaboração específica de normas a respeito disso, o ordenamento jurídico brasileiro possui dispositivos constitucionais e tratados internacionais que dão suporte de validade à tutela dos indivíduos que se encontram em situações de deslocamento forçado, em decorrência de ausência de recurso hídricos, cabendo ao Estado efetivar seu papel para assegurar a consecução de sua finalidade institucional, que é a proteção da pessoa humana.

Os deslocados, por serem pessoas humanas, são merecedores de proteção, preservando-se sua dignidade, e de todos os direitos e garantias fundamentais reconhecidos pela Constituição Federal de 1988 e demais garantias que a Declaração Universal dos Direitos Humanos Ihes concede.

Conclui-se que os sujeitos que se deslocam dentro do território nacional, em virtude de questões hídricas, são resguardados tanto pelas normas de direito interno, que tratam principalmente das garantias e dos direitos fundamentais das pessoas humanas, quanto por normas de direito internacional, que asseguram a tutela desses sujeitos, independentemente de inexistir previsão legislativa específica para o caso. 


\section{REFERÊNCIAS}

ARAÚJO, Luiz Alberto David; NUNES JÚNIOR, Vidal Serrano. Curso de direito constitucional. 8. ed. São Paulo: Saraiva, 2004.

BERTOLO, Rubens Geraldi. Inviolabilidade do domicílio. São Paulo: Método, 2003.

BRASIL. Constituição da República Federativa do Brasil, de 5 de outubro de 1988. Disponível em: <https://www.planalto.gov.br/ccivil_03/constituicao/constituicao. htm>. Acesso em: 8 dez. 2016.

. Emenda Constitucional n. 1, de 17 de outubro de 1969. Edita o novo texto da Constituição Federal de 24 de janeiro de 1967. Disponível em: <http://www. planalto.gov.br/ccivil_03/Constituicao/Emendas/Emc_anterior1988/emc01-69. htm>.

. Constituição da República dos Estados Unidos do Brasil. 1967. Disponível em: <http://www.planalto.gov.br/ccivil_03/constituicao/constituica067.htm>. Acesso em: 16 nov. 2016.

. Constituição da República dos Estados Unidos do Brasil. 1946. Disponível em: <https://www.planalto.gov.br/ccivil_03/Constituicao/Constituicao46.htm>. Acesso em: 16 nov. 2016.

. Constituição da República dos Estados Unidos do Brasil. 1937. Disponível em: <https://www.planalto.gov.br/ccivil_03/constituicao/Constituicao37.htm>. Acesso em: 16 nov. 2016.

. Constituição da República dos Estados Unidos do Brasil. 1934. Disponível em: <http://www.planalto.gov.br/ccivil_03/Constituicao/Constituicao34.htm>. Acesso em: 16 nov. 2016

. Constituição da República dos Estados Unidos do Brasil. 1891. <http:// www.planalto.gov.br/ccivil_03/Constituicao/Constituicao91.htm>. Acesso em: 16 nov. 2016.

. Constituição Política do Império do Brazil. 1824. Disponível em: <https:// www.planalto.gov.br/ccivil_03/constituicao/constituicao24.htm>. Acesso em: 16 nov. 2016.

BULOS, Uadi Lammêgo. Constituição Federal anotada. 4. ed. São Paulo: Saraiva, 2002.

CANOTILHO, José Joaquim Gomes. Direito constitucional e teoria da constituição. 2. ed. Coimbra: Almedina, 1998.

GARRIDO, Diego Lopes; GARROTE, Marcos Francisco Massó; PEGORARO, Lúcio. Nuevo derecho constitucional comparado. Valencia: Irant lo blanch, 2000. 
MENDES, Gilmar Ferreira; COELHO, Inocêncio Mártires; BRANCO, Paulo Gustavo Gonet. Curso de direito constitucional. 5. ed. São Paulo, Saraiva, 2007.

MORAES, Alexandre de. Direitos humanos fundamentais. 5. ed. São Paulo: Atlas, 2003.

PACTO INTERNACIONAL DOS DIREITO CIVIS E POLÍTICOS (PCP). 1966. Disponível em: <http://www.dhnet.org.br/direitos/sip/onu/doc/pacto2.htm>. Acesso em: 16 nov. 2016.

PACTO INTERNACIONAL DOS DIREITOS ECONÔMICOS, SOCIAIS E CULTURAIS (PESC). 1966. Disponível em: <http://www.unfpa.org.br/Arquivos/pacto_internacional. pdf>. Acesso em: 16 nov. 2016.

PIOVESAN, Flávia. Direitos humanos e o direito constitucional internacional. 4. ed. São Paulo: Max Limonad, 2000.

PRINCÍPIOS ORIENTADORES DOS DESLOCADOS INTERNOS. 1998. Disponível em: <http://www.ohchr.org/Documents/Issues/IDPersons/GPPortuguese.pdf>. Acesso em: 16 nov. 2016.

REZEK, José Francisco. Direito internacional público. 9. ed. São Paulo: Saraiva, 2002.

SARLET, Ingo Wolfgang; FENSTERSEIFER, Tiago. Direito constitucional ambiental. 2. ed. São Paulo: Revista dos Tribunais, 2012.

TAVARES, André Ramos. Curso de direito constitucional. São Paulo: Saraiva, 2002. UNESCO. Declaração Universal dos Direitos do Homem. 1948. Disponível em: <http://unesdoc.unesco.org/images/0013/001394/139423por.pdf>. Acesso em: 16 nov. 2016. 
